\title{
TIRO À QUEIMA-ROUPA
}

\author{
MACHO NÃO GANHA FLOR,
}

de Dalton Trevisan. Rio de Janeiro: Record, 2006.

BERTA WALDMAN

[1] Dalton Trevisan, O Vampiro de Curitiba. ( $3^{\text {a }}$ edição rev.) Rio de Janeiro: Civilização Brasileira, 1974.

\footnotetext{
[2] Dalton Trevisan, Novelas nada exemplares. Rio de Janeiro:José Olympio Ed., 1959 .

[3] Joaquim (Dir. Dalton Trevisan). Curitiba, abril de 1946 a dezembro de 1948, 21 números. Edição fac-similar, Imprensa Oficial do Paraná, 2001 (org. Miguel Sanches Neto).

[4] Dalton Trevisan, O rei da Terra. Rio de Janeiro: Civilização Brasileira, 1972.
}

\section{"Para escrevero menor dos contos a vida inteira é curta"1}

Nascido em 1925, em Curitiba, Dalton Trevisan é um escritor que não faz concessões: não dá entrevistas, não se deixa fotografar, não conversa com leitores, não recebe prêmios, nem participa de encontro de escritores. Sem contar os textos publicados em folhetos distribuídos de mão em mão ou enviados pelo correio, seu primeiro livro é de 1959, Novelas nada exemplares ${ }^{2}$. Antes dessa data participou ativamente da organização da revista modernista curitibana Joaquim ${ }^{3}$, cujo primeiro número é de abril de 1946. Nela publicou vários textos. Contando hoje com uma vasta e significativa obra, Trevisan é um escritor programático e obsessivo que traça o itinerário de uma busca incessante, manifestada na repetição de situações, de personagens, de um tema que se multiplica em voltas infindáveis. Até 1972, com a publicação de O rei da Terra ${ }^{4}$, as narrativas de Trevisan são mais extensas porque a investigação da matéria literária tem peso grande e, na medida em que a matéria se circunscreve, com ela vem o enxugamento da linguagem, que sempre se inova, para, por seu intermédio, dar relevo estético e histórico para as coisas de seu tempo e lugar. Nesse sentido, a Curitiba que emerge dos seus contos, à maneira do que acontece com o Nordeste de Graciliano Ramos ou o sertão de Guimarães Rosa,é o próprio mundo, porque o mundo também é Curitiba no que tem de grotesco e regressivo. Em outras palavras, a medida de um escritor, principalmente nos países periféricos como o Brasil, deriva, em grande parte, de um tipo de agudeza - da agudeza para perceber que a complexidade do mundo contemporâneo também se expressa aqui, e que uma representação artística eficaz dele contribui para a imagem do conjunto.

Escolhendo a periferia da periferia, desfilam sob um facho de luz fria funcionários públicos, lojistas, prostitutas, donas de casa, domésticas, profissionais liberais, normalistas, trabalhadores da terra, mon- 
tando a cena ficcional de Trevisan como um universo sem saída, objetivando, entre nós, a negatividade de uma obra construída segundo a melhor tradição literária no mapa da narrativa contemporânea.

A partir de 1974, com $O$ pássaro de cinco asas 5 , o autor radicaliza a redução da linguagem, tomando como alvo o haicai, as "ministórias" (neologismo do autor), a palavra descarnada. Trevisan passa a praticar diferentes experiências formais, verticalizando o conto recortado em verso, propondo poemas, reduzindo o conto a "ministória", enquanto amplia, enxuga e cria novos ritmos. Diminui, em geral, a extensão dos contos, e a frase é golpeada, fragmenta-se, eliminam-se verbos, conjunções, pronomes, adjetivos, evita-se a subordinação e delineia-se a oração nominal como predileta. Concomitante a essa redução, faz-se um recorte mais exigente do universo de personagens que vai se acuando à periferia, em consonância com a história presente do país, onde os desempregados, excluídos, marginais e sem perspectivas formam maioria cada vez mais visível.

É mais ou menos nessa moldura que se inscreve o último livro de Dalton Trevisan, Macho não ganha flor. ${ }^{6} \mathrm{O}$ primeiro conto, que dá nome ao livro, começa em clima romântico, com uma jovem de roupão, prestes a entrar no banho, numa tarde de sol, ao som do canto de corruíras. De repente, a moça-narradora percebe que não está sozinha na casa, desponta um estuprador que, imediatamente, abre o roupão e tem início uma peleja sexual feita de gemidos, esfregas, nojo, medo, choro, zíper, calcinha, seio, mão boba, arranca, esgoela, até que a mocinha se dá conta "que ele tentava, mas não conseguia". Macho ofendido, a culpaé dela, Eva é culpada. Ele sai roubando e assim compensa a tentativa frustrada de dominação sexual.

Este conto dá o tom aos demais: o clima de folia fescenina, linguagem chula, obscenidade, domínio da intimidade escancarada, desejo e perversão sexual emulados pela violentação do outro são dados que transparecem na obra inteira.

Em "O vestido vermelho", a narradora, ao contrário da anterior, apela para que o amante volte. Ela deseja ser violentada e para isso veste vermelho, a cor da sedução:

"Quem não sabe que o meu amor é tarado por uma violação? Que só pensa em enfiar, meter, arrombaro meu corpo e currar a minha alminha."(p.23)

"Do macho a gente espera fatal! O beijinho molhado e o tabefe ardido de mão aberta.

Mas onde está você, cego e surdo, que não responde?"(p.22)

Ao mesmo tempo em que existe um imaginário erótico masculino, eleé também feminino, pois a mulher o incorpora para se tornar sedutora ao homem. Mas quando ele a quer, ela não o quer, evice-versa, instaurando o malfadado desencontro. O encontro nunca é natural, às
[5] Dalton Trevisan, $O$ pássaro de cinco asas. Rio de Janeiro: Civilização Brasileira, 1974.

[6] Dalton Trevisan, Macho não ganha flor. Rio de Janeiro: Record, 2006. 
vezes ele é forçado. Em "Ai, ai, eu morro", ele, de faquinha na cinta, bêbado, esfaqueia a mulher na barriga, porque ela, também bêbada, se queixa de que ele está pesando em seu ombro, enquanto caminham.

"Eu desmaiei e logo acordei. Já viu uma cachorra atropelada no meio da rua? Essa era eu. Me arrastava ali no chão. Um bando de caras nojentas em volta. Bem que apreciavam o quadro. Toda meesvaía pelas três bocas abertas na barriga." (p.61) Depois de quatro meses de recuperação, "Agora a gente tá junto de novo. Assim que me força pra ficar com ele. E não dá jeito de conhecer um cara legal." (p.61)

Quanto aos narradores homens, em "Isso aí, malandro", um assaltante conta a experiência de roubar um casarão, a emoção do risco e o relato de sexo entremeado com roubo: "Se aparece uma dona pela frente periga ter de abrir as pernas. Isso aí, chefia. Por bem ou por mal. Não dá pra segurar." (p.16) Também fios autobiográficos do narrador emergem: a filha "tava com seis meses, uma pombinha do céu. Só porque chorava, a mãe afogou no travesseiro." Seguindo o assassinato da filha, o abandono da mulher que se ligou a um viciado em pó e pedra "Ele é do mal". Na terceira investida ao casarão, o narrador é pego pelo vigia, e os dois acabam dividindo o butim do roubo. Roubo, estupro, assassinato, droga, bebida, alcagüetagem, identificação entre ladrão e polícia, transitam por outros contos. Também a falta de solidariedade entre pares, o gesto gratuito de violência, a exploração da prostituta pelo freguês bacana e pelo gigolô, o abuso sexual de crianças complementam esse quadro em que não existe mais vestígio do bem. Não há princípio moral ou lei que se sustente, não escapa nem mesmo o estupro de uma mãe pelo próprio filho. Em "O menino de sua mãe", a narradora é a mãe que conta que seu filho afogou seu pescoço, riscou de leve o estiletee

"sem mais palavra, penetrou./.../lembro ter pensado: 'Antes eu, e não outra'. Que outra iria se conformar? Se o teu filho é pirado, até isso você deve sofrer. Quando todos condenam, não é a mãe que perdoa sempre?" (p.75)

Personagem que retorna de outros livros, uma estudante de uniforme escolar narra a projeção de suas aventuras com o Dr. João, da Academia de Letras, um velho safado, em "Prova de redação". Sua colega que passou pela experiência conta todos os passos da sedução, e a jovem os repete para o leitor. Ao repetir, o autor usa uma estratégia de linguagem em que "eu" equivale a "ela":

"E ela? eu? geme e grita e goza, erguendo os braços bem alto. Ai, ai, ai. E com a pontinha do dedo roça na asa do arcanjo que passa.

/.../E manda que eu? ela? diga palavra porca. Eu digo e repito o que o doutor ensinar." (p.112)

As cenas amorosas seguem um só roteiro, as marcações são as mesmas, assim "eu" e "ela" oscilam mas apontam para uma prática idên- 
tica. Neste sentido os pronomes se equivalem. Transformado em atividade puramente mecânica, o sexo predica a ausência de um sujeito. Predica o vazio. Assim, o relato em primeira pessoa não supõe um enfoque pessoal, a manifestação da personagem-narradora em pleno ato presente, como um "eu" que ocupa totalmente a tela imaginária da narrativa, porque há entre o "eu" e o narrado a mediação de um objeto que reaparece: a linguagem.

Escuta atenta e aguda, o autor registra falas de grupos e as põe em circulação em seus livros. Variadas, facilmente identificadas pelo leitor, o autor as vai atualizando. Assim, em obras mais recentes, ganha espaço o discurso do viciado em crack, do cheirador de pó, do traficante, ou a inclusão de falas relacionadas a seitas e grupos religiosos divulgados pela mídia, que trazem a promessa de se montar uma vida espiritual pelo prefixo telefônico 0800 , em ligação direta com deus. Esses discursos deslocados do real para a ficção compõem com breves pinceladas uma espécie de "quadro vivo" concentrado no essencial, sem alçapões ilusionistas, nem jogos de luz enganadores. Funcionando como moeda corrente, essas falas são dessubjetivadas, não se ligam a um corpo, correm soltas na boca da jovem, da velha, do malandro, do pivete que passa, do bacana, da mulher, do doutor.Lapidadas a faca, o autor, mestre minimalista, as recorta, subtrai e decanta os restos, imprime-lhes um ritmo que quase prescinde do uso de pontuação. Essa linguagem provoca, sem dúvida, uma boa dose de desindividualização da matéria narrada. Utilizada, ela transforma a personagem em portador abstrato, não um "eu" que se conta ou conta o mundo através dela, é a linguagem que se emancipa, toma rumo próprio, alheio às intenções de qualquer subjetividade. Expressão da violência também no modo direto com que aborda sua matéria, a linguagem é incisiva, licenciosa, compacta, tem a precisão de um tiro à queima-roupa, que não prescinde de boa dose de humor. É difícil, entretanto, sustentar o riso quando o leitor se dá conta de que o que se apresenta é um mundo sem sentido e sem saída em relação ao qual ele quer estabelecer distância, mas é obrigado a se enxergar nele. Esse mundo calcado no negro perdeu o céu como parâmetro, detendo-se num corpo-a-corpo com o real, sem o anteparo de qualquer idealização ou promessa de redenção.

Para forçar a difícil identificação do leitor com as personagens em situação, uma das estratégias do autor é fazer deslizar a primeira para a segunda pessoa de modo a implicar também aquele que lê na matéria narrada:

"Grudados na tua nuca os mil olhos dos cagüetas da Vila". (p.15) (grifo meu)

"Se o teu filho é pirado, até isso você deve sofrer." (p.75) (grifo meu)

A segunda pessoa inclui o leitor, em quem também respinga a vio- 
lência dos atos, transformando a todos em co-participantes da vida nua, feita da distribuição global de miséria e morte.

É sempre a linguagem feita (algo como um ready made - mas trabalhado), que carrega uma história própria, e o autor a traz para os contos para reduplicar os estereótipos sociais. Entretanto, ocorre uma reversão na passagem da ordem histórica para a ordem ficcional, e a linguagem passa a peça articulada que, em sua inteireza artística, mantém inteligível a imagem do grotesco e da alienação do grupo em que circula.

Os contos de Dalton Trevisan, apesar da proximidade que mantêm com sua matéria, instituem um outro princípio de realidade através do estranhamento. Pois é só quando quebra com o existente que a ficção realiza sua função cognitiva, comunicando sensações, intuições, "verdades" que o mais das vezes não são transmissíveis de outro modo.É nesse sentido que ela contra-diz, e é nesse sentido também que ela é subversiva. A representação formal do mundo de Dalton Trevisan se faz então através de uma linguagem rebaixada que o autor desgasta e explora com esmero e rigor, reduzindo-a ao mínimo, ao osso, tiro no coração do leitor.

BERTA WALDMAN é professora de Literatura Hebraica na USP e de Literatura Brasileira na Unicamp. 